\title{
PENDAMPINGAN PEMANFAATAN BANTUAN PERALATAN PENGOLAHAN PANGAN DI KIMTRANS SUNGAI BESAR SP-1, KABUPATEN KETAPANG, PROVINSI KALIMANTAN BARAT
}

\author{
Mohamad Haifan 1), Iyus Hendrawan ${ }^{2)}$ \\ ${ }^{1}$ Prodi Teknik Mesin Otomotif, Institut Teknologi Indonesia \\ haifan63@yahoo.com \\ ${ }^{2}$ Prodi Teknik Mesin, Institut Teknologi Indonesia \\ iyushendrawan@yahoo.com
}

\begin{abstract}
To increase the income and welfare of transmigrant residents can be done through the development of agricultural processing business based on the potential of the region.. To achieve this, the Government through the Directorate of Business Development, Directorate General of Transmigration Area Development, Ministry of Village, Disadvantaged Area Development and Transmigration has provided machinery and processing equipment to manage and develop micro and small scale agroindustry at transmigration settlements. However, the aid of machinery and processing equipment of such products faced obstacles and problems in the field of utilization and management that have not been optimal, so it has not been able to encourage the growth of activities of processing and entrepreneurship results. Therefore, it is necessary to provide assistance and empowerment of transmigrant residents for the utilization of machinery and processing equipment. The purpose of this activity is to identify the aid of machinery and processing equipment at location and to assist and mobilize the transmigrants to build awareness and skills of agricultural processing practices. From the results of the assistance activities for four months, can be identified the aid of machinery and processing equipment as many as 59 units with various conditions. In addition, assistance and empowerment activities can build awareness, independence and skills in the processing of agricultural products, such as cassava chips, nuggets, meatballs, noodles and pineapple that can be one source of income transmigrant residents.
\end{abstract}

Keyword : Transmigration settlements, empowerment, machine and processing equipments

\section{PENDAHULUAN}

\section{Latar Belakang}

Program transmigrasi merupakan upaya mempercepat pembangunan kawasan yang masih tertinggal guna meningkatkan kesejahteraan transmigran dan penduduk sekitar [1]. Sampai tahun 2016 tercatat sekitar 20 juta penduduk telah mengikuti program transmigrasi. Jika ukuran keberhasilan transmigrasi hanya dari sisi kuantitas, maka program transmigrasi bisa diklaim sebagai program yang berhasil. Namun pada prakteknya, ada ukuran keberhasilan lainnya yaitu kesejahteraan keluarga transmigran [2].

Pengembangan usaha ekonomi di Kawasan Permukiman Transmigrasi (Kimtrans) melalui kegiatan pengolahan hasil pertanian pada dasarnya merupakan bagian dari upaya meningkatkan nilai tambah terhadap hasil produksi pertanian masyarakat transmigrasi. Tujuan kegiatan ini adalah untuk mewujudkan peningkatan pendapatan dan kesejahteraan warga transmigran dan masyarakat sekitar melalui pengembangan usaha pengolahan hasil pertanian yang berbasis pada potensi wilayah yang dikelola secara mandiri, modern dan berdaya saing .

Dalam mewujudkan tujuan di atas, maka Pemerintah melalui Direktorat Pengembangan Usaha, Direktorat Jenderal Pengembangan Kawasan Transmigrasi, Kementerian Desa, Pembangunan Daerah Tertinggal dan Transmigrasi telah memberikan bantuan mesin dan peralatan pengolahan hasil untuk mewujudkan pengembangan agroindustri skala mikro dan kecil di Kimtrans. Namun bantuan mesin dan peralatan pengolahan hasil tersebut menghadapi kendala dan permasalahan di lapangan yaitu pemanfaatan dan pengelolaannya yang belum optimal, sehingga belum mampu 
mendorong tumbuh kembangnya kegiatan pengolahan hasil dan kewirausahaan di Kimtrans.

Beberapa kendala yang mengakibatkan belum optimalnya pemanfaatan dan pengelolaan mesin dan peralatan pengolahan hasil, diantaranya masalah teknis, budaya dan kelembagaan pengelola. Untuk mengatasi permasalahan tersebut, maka perlu dilakukan kegiatan pendampingan teknis mesin dan peralatan pengolahan, pengelolaan usaha pengolahan hasil pertanian serta pemasarannya.

\section{Program Pendampingan dan Pemberdayaan Masyarakat Transmigran}

Pemukiman transmigrasi mempunyai potensi sumberdaya sumber daya alam yang sangat besar, namun terdapat beberapa kendala, diantaranya faktor topografi, kekurangan sumberdaya manusia untuk mengelolanya (baik jumlah maupun ketrampilan), sehingga untuk mengelola sumberdaya alam yang tersedia perlu mengembangkan sumberdaya manusia yang terampil dan berkualitas.

Pendampingan sebagai suatu strategi yang umum digunakan oleh pemerintah dan lembaga non profit dalam upaya meningkatkan mutu dan kualitas dari sumber daya manusia, sehingga mampu mengindentifikasikan dirinya sebagai bagian dari permasalahan yang dialami dan berupaya untuk mencari alternatif pemecahan masalah yang dihadapinya. Pada kegiatan pendampingan dilakukanoleh fasilitator (sering disebut fasilitator masyarakat), karena tugasnya lebih sebagai pendorong, penggerak, katalisator, motivator masyarakat, sementara pelaku dan pengelola kegiatan adalah masyarakat itu sendiri.

Sementara itu, pendampingan masyarakat adalah strategi pembangunan yang biasanya dihubungkan dengan konsep sendiri, partisipasi jaringan kerja dan keadilan. Pada dasarnya diletakkan pada kekuatan tingkat individu sosial, dimana partisipasi merupakan komponen penting dalam pembangkitan kemandirian dan proses pemberdayaan. Masyarakat harus terlibat dalam proses tersebut, sehingga mereka dapat memperhatikan hidupnya untuk memperoleh rasa percaya diri, memliki harga diri dan pengetahuan untuk mengembangkan keahlian baru melalui proses komulatif yang menghasilkan perbaikan dan banyak ketrampilan yang dimiliki, sehingga semakin baik kemampuan berpartisipasinya. Kemampuan sumber daya manusia sangat dipengaruhi oleh keberdayaan dirinya sendiri. Oleh karena itu, sangat dibutuhkan kegiatan pemberdayaan disetiap kegiatan pendampingan.

Pemberdayaan adalah upaya yang membangun daya masyarakat dengan mendororng, memotivasi dan membangkitkan kesadaran akan potensi yang dimiliki serta berupaya untuk mengembangkannya [3].

Pemberdayaan masyarakat tidak lain adalah memberikan motivasi dan dorongan kepada masyarakat agar mampu menggali potensi dirinya dan berani bertindak memperbaiki kualitas hidupnya, melalui cara antara lain dengan pendidikan untuk penyadaran dan pemampuan diri mereka. Tujuan akhir dari proses pemberdayaan masyarakat adalah untuk memandirikan warga masyarakat agar dapat meningkatkan taraf hidup keluarga dan mengoptimalkan sumberdaya yang dimilikinya [4].

Pemberdayaan masyarakat transmigrasi adalah upaya-upaya yang dilakukan dalam rangka meningkatkan kemampuan masyarakat yang berbasis agribisnis, sehingga secara mandiri mampu mengembangkan diri dan dalam melakukan usaha secara berkelanjutan. Menghidupkan kembali berbagai pranata ekonomi masyarakat untuk dihimpun dan diperkuat, sehingga dapat berperan sebagai lokomotif bagi kemajuan ekonomi merupakan keharusan untuk dilakukan. Ekonomi rakyat akan terbangun bila hubungan sinergis dari berbagai pranata sosial dan ekonomi yang ada didalam masyarakat dikembangkan kearah terbentuknya jaringan ekonomi rakyat.

Pemberdayaan diarahkan guna meningkatkan ekonomi masyarakat secara produktif sehingga mampu menghasilkan nilai yang tinggi dan pendapatan yang lebih besar. Upaya peningkatan kemampuan untuk menghasilkan nilai tambah harus ada perbaikan akses terhadap empat hal, yaitu akses sumber daya, akses terhadap 
teknologi, akses permodalan dan akses terhadap pasar [5]. Pemberdayaan sosial ekonomi pada intinya dapat diupayakan melalui berbagai kegiatan antara lain pelatihan, pendampingan, penyuluhan, pendidikan dan keterlibatan organisasi demi menumbuhkan dan memperkuat motivasi hidup dan usaha, serta pengembangan pengetahuan, keterampilan hidup dan kerja.

\section{METODE}

Kegiatan pengabdian kepada masyarakat dilaksanakan di Permukiman Transmigrasi Sungai Besar SP-1, Kabupaten Ketapang, Provinsi Kalimantan Barat. Waktu pelaksanaan kegiatan antara bulan Agustus sampai Desember 2015.

Kegiatan pendampingan terdiri atas tiga kegiatan, yaitu :

1) Identifikasi dan inventarisasi bantuan mesin dan peralatan pengolahan pangan di lokasi Kimtrans,

2) Pendampingan teknis dan peningkatan kapasitas sumberdaya manusia yang meliputi kegiatan pendampingan untuk pemahaman karakterisitik peralatan, rekondisi/perbaikan menyeluruh dan atau melakukan penyesuaian spesifikasi mesin dan peralatan pengolahan hasil sesuai kebutuhan agar dapat dimanfaatkan secara tepat guna dan memiliki kinerja yang optimal, perawatan peralatan, membuat kesepakatan antara pengelola Poktan/Gapoktan dan Kelompok Usaha Transmigran.

3) Memberikan pelatihan pemanfaatan mesin dan peralatan pengolahan untuk pengolahan hasil pertanian potensi lokasi, membangun pemahaman kewirausahaan warga transmigran.

\section{HASIL DAN PEMBAHASAN Profil Kimtrans Sungai Besar SP-1}

Kondisi topografi Kimtrans Sungai Besar SP-1 terdiri atas dataran datar (0-3\%) seluas $298 \mathrm{Ha}(26,13 \%)$, dataran berombak (3-8\%) seluas 444,20 Ha (38,83\%), dataran agak bergelombang (8-15\%) seluas $347 \mathrm{Ha}$ $(30,33 \%)$ dan dataran bergelombang (15$25 \%$ ) seluas 53,90 Ha (4,71\%), sehingga total luasan sebesar 1.144,00 Ha.

Potensi lahan dan kegiatan usaha tani warga ransmigran di Kimtrans Sungai Besar SP-1 meliputi tanaman pangan (padi, jagung, kacang tanah, kedelai, ubi kayu, ubi jalar), tanaman hortilkultura (buah-buahan dan sayuran) dan tanaman perkebunan (kelapa, kopi, lada dan kelapa sawit).

Jumlah transmigran yang telah ditempatkan di Kimtrans Sungai Besar SP1, Kabupaten Ketapang, Provinsi Kalimantan Barat pada tahun 2010-2011 sebanyak $700 \mathrm{KK}$ (1.326 Jiwa) yang terdiri atas laki-laki sebanyak 710 Jiwa dan perempuan sebanyak 616 Jiwa.

Tabel 1. Fasilitas Umum Terbangun di Kimtrans Sungai Besar SP-1

\begin{tabular}{clcc}
\hline No & Jenis Bangunan/ Fasilitas & Jumlah (Unit) & Keterangan \\
\hline 1 & Kantor UPT & 1 & Rusak Sedang \\
\hline 2 & Rumah Petugas & 1 & Rusak Sedang \\
\hline 3 & Balai Desa & 1 & Rusak Sedang \\
\hline 4 & Puskemas Pembantu & 1 & Rusak Sedang \\
\hline 5 & Posyandu & - & - \\
\hline 6 & Masjid/ Mushola & 1 & Rusak Sedang \\
\hline 7 & Gudang & 1 & Rusak Sedang \\
\hline 8 & Gedung Sekolah & $1 \mathrm{SD}$ & Baik \\
\hline 9 & Jalan Poros & $2,6 \mathrm{Km}$ & Rusak Ringan \\
\hline 10 & Jalan Desa & $2,0 \mathrm{Km}$ & Rusak Ringan \\
\hline
\end{tabular}

Sumber : KUPT Kimtrans Sungai Besar SP-1

\section{Identifikasi dan Inventarisasi Mesin dan Peralatan Pengolahan Hasil}

Hasil identifikasi bantuan alsintan dan peralatan pengolahan hasil yang pernah diberikan oleh pemerintah melalui Kementerian Desa, Pembangunan daerah 
Tertinggal dan Transmigrasi (APBN) kepada Kimtrans Sungai Besar SP-1, Kabupaten Ketapang, Provinsi Kalimantan Barat disajikan pada Tabel 2. Dari tabel tersebut tercatat sebanyak 59 unit bantuan mesin dan peralatan pengolahan hasil dengan berbagai kondisinya di lokasi.

Tabel 2. Jenis, Jumlah dan Kondisi Alsintan di Kimtrans Sungai Besar SP-1

\begin{tabular}{|c|c|c|c|c|c|c|}
\hline No & Nama Alat & $\begin{array}{c}\text { Jumlah } \\
\text { (Unit) }\end{array}$ & Merk/ Type & Sumber & Kondisi & Keterangan \\
\hline 1 & Hand Traktor & 7 & $\begin{array}{l}\text { Agrindo/ } \\
\text { TRG } 1 \text { A }\end{array}$ & APBNP & Baik & $\begin{array}{l}\text { Sudah beroperasi/ } \\
\text { termanfaatkan }\end{array}$ \\
\hline 2 & Pompa Air & 7 & & APBN & Baik & Belum termanfaatkan \\
\hline 3 & Handsprayer & 28 & & APBN & Baik & $\begin{array}{l}\text { Sudah beroperasi/ } \\
\text { termanfaatkan }\end{array}$ \\
\hline 4 & Gerobak Bermotor & 3 & VIAR/ 150L & APBN & Baik & 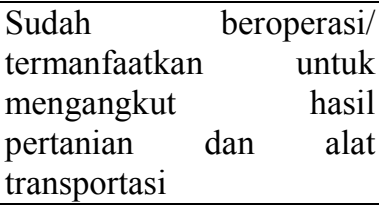 \\
\hline 5 & $\begin{array}{l}\text { Mesin Perontok Padi } \\
\text { Multi Guna }\end{array}$ & 2 & $\begin{array}{l}\text { Agrindo/ } \\
\text { TPA } 1000 \\
\text { MG }\end{array}$ & APBN & Baik & $\begin{array}{l}\text { Sudah beroperasi/ } \\
\text { termanfaatkan. Diluar } \\
\text { musim panen motor } \\
\text { penggerak digunakan } \\
\text { sebagai penggerak genset }\end{array}$ \\
\hline 6 & Pemipil Jagung & 1 & & APBN & Baik & $\begin{array}{l}\text { Sudah beroperasi/ } \\
\text { termanfaatkan }\end{array}$ \\
\hline 7 & Rice Milling Unit (RMU) & 2 & $\begin{array}{l}\text { Satake/ } \\
\text { SB 10 D }\end{array}$ & APBN & Baik & Belum termanfaatkan \\
\hline 8 & Hand Sealer & 1 & PCS-3001 & APBN & Baik & Belum termanfaatkan \\
\hline 9 & Mesin Penggiling Daging & 1 & - & APBN & Baik & Belum termanfaatkan \\
\hline 10 & $\begin{array}{l}\text { Alat Pengiris Singkong/ } \\
\text { Slicer }\end{array}$ & 1 & MG-300 & APBN & Baik & Belum termanfaatkan \\
\hline 11 & Timbangan Besar & 2 & $\begin{array}{l}\text { Camri/ EK- } \\
26\end{array}$ & APBN & Baik & Belum termanfaatkan \\
\hline 12 & Timbangan Kecil & 1 & Hiosi & APBN & Baik & Belum termanfaatkan \\
\hline 13 & $\begin{array}{l}\text { Mesin Pembuat Mie ( } \\
\text { Manual Noodle Maker) }\end{array}$ & 1 & ATL 150 & APBN & Baik & Belum termanfaatkan \\
\hline & Timbangan Digital & 2 & & APBN & Baik & $\begin{array}{l}\text { Sudah beroperasi/ } \\
\text { termanfaatkan }\end{array}$ \\
\hline
\end{tabular}

\section{Jumlah $\quad 59$}

Sumber : Hasil Survei dan Pendampingan, 2015

\section{Pendampingan Pemanfaatan Mesin dan Peralatan Pengolahan Hasil}

Pendampingan dan pelatihan yang diberikan kepada warga transmigran meliputi : a) motivasi pemanfaatan alsintan dan aplikasinya dalam kehidupan petani, khususnya dengan memanfaatkan potensi hasil pertanian di lokasi transmigrasi, b) pengolahan keripik singkong, c) pengolahan dodol nenas, d) pengolahan bakso, e) pengolahan nugget, f) pengolahan mie, dan g) aspek manajerial pengelolaan usaha secara sederhana.
Pelaksanaan pelatihan diikuti oleh 13 orang, dimana peserta aktif mengikuti pelatihan dengan partisipasi dan masukan yang cukup interaktif. Peserta memahami bahwa potensi alam dan hasil pertanian dapat ditingkatkan manfaatnya dengan pengolahan sederhana. Praktek pengolahannya dibagi menjadi dua kelompok, yaitu kelompok ibu-ibu dan kelompok bapak-bapak. Kelompok ibu-ibu melakukan praktek pembuatan keripik singkong, dodol nenas mie, bakso dan nugget menggunakan peralatan yang sudah dibantukan. 


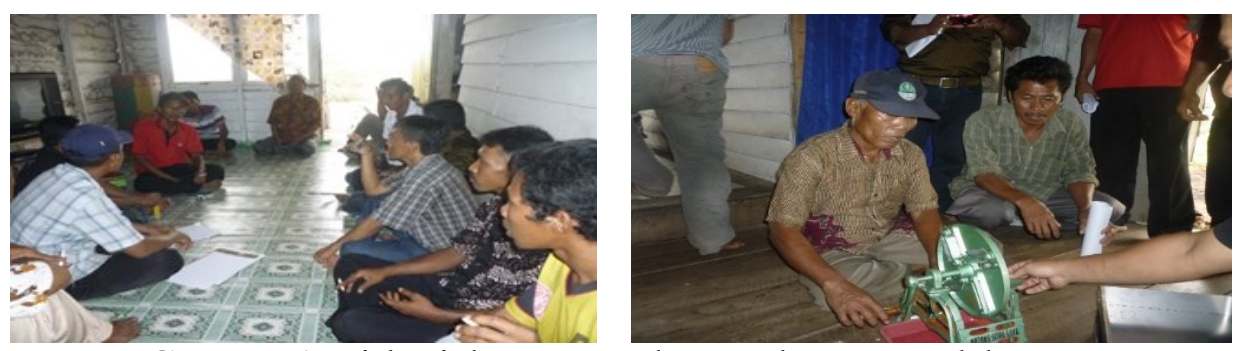

Gambar 1. Diskusi dan Pengenalan Peralatan Pengolah Pangan
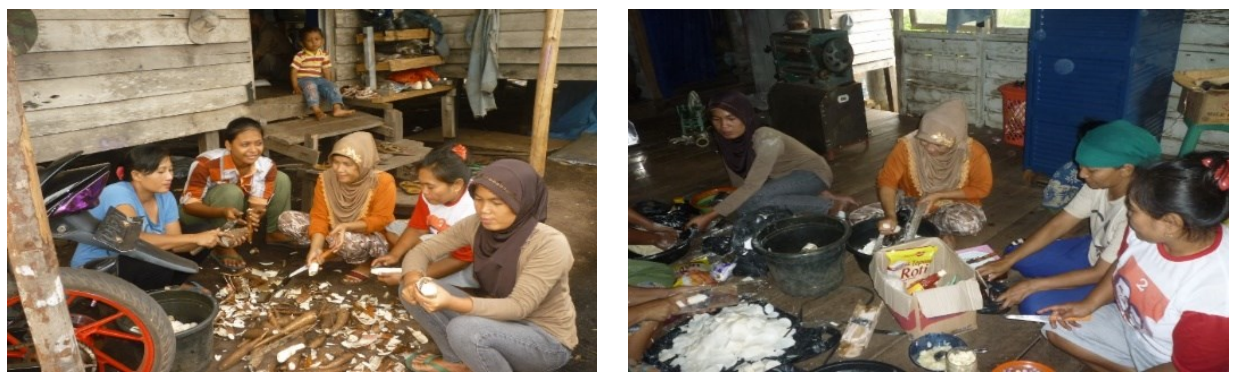

Gambar 2. Pengolahan Kripik Singkong

Dilakukan pengembangan produk menggunakan seasoning (rasa keju dan rasa jagung bakar) untuk meningkatkan kualitas dan variasi produk. Produk berhasil dibuat dan dicoba, peserta menilai bahwa produk yang dihasilkan cukup baik dan enak, mereka sangat antusias untuk memproduksi dan mengembangkannya menjadi usaha produktif. Peserta bapak-bapak melakukan diskusi tentang peralatan pertanian yang diperbantukan.
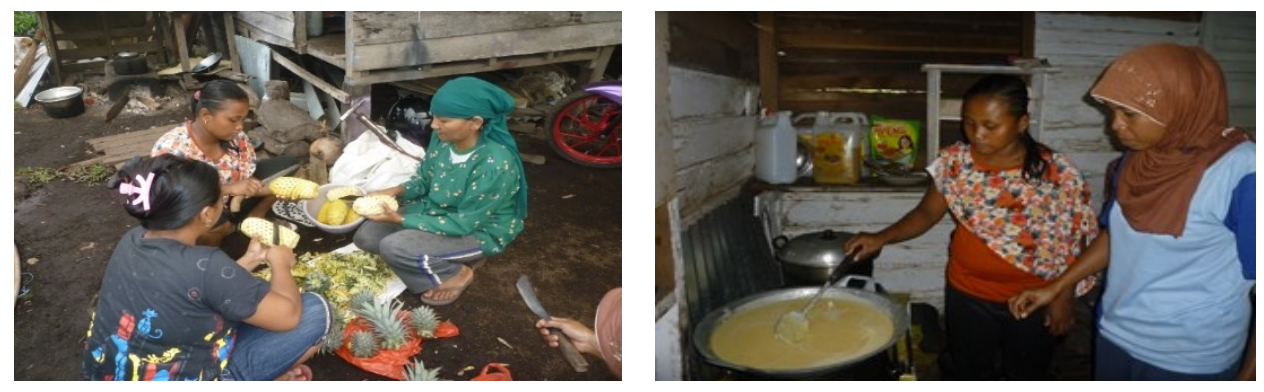

Gambar 3. Pengolahan Dodol Nanas
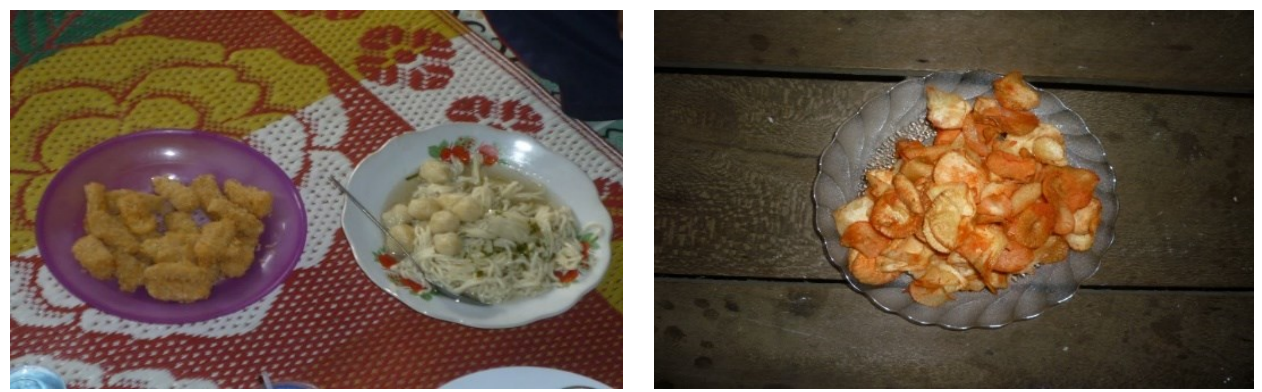

Gambar 4. Hasil Olahan Nugget, Mie Bakso dan Kripik Singkong

Beberapa kendala yang dihadapi dalam pengembangan kegiatan agroindustri dan kewirausahaan terkait dengan pemanfaatan alsintan dan peralatan pengolah hasil, diantaranya : 
a. Alat perajang singkong semi otomatis mata pisaunya terbalik, sehingga tidak bisa menghasilkan irisan yang halus,

b. Aspek permodalan yang menghambat usaha produktif

Beberapa usulan untuk rencana pengembangan (action plan) kegiatan agroindustri dan kewirausahaan di Kimtrans Sungai Besar SP 1 adalah :

a. Produk yang direkomendasikan adalah keripik singkong dengan berbagai rasa. Potensi hasil pertanian sangat mendukung, sementara ibu-ibu kelompok tani di lokasi transmigrasi rata-rata sudah memiliki keterampilan dalam membuat keripik. Hal baru yang diperkenalkan pada pelatihan adalah pengembagan keripik dengan berbagai rasa. Variasi rasa tersebut sangat disukai oleh peserta, demikian juga oleh anak-anak mereka yang menyaksikan pelatihan. Dengan respon yang bagus itu peserta merasa optimis produk tersebut dapat dipasarkan dengan lebih luas. Seperti diketahui, di daerah tersebut sudah ada pengusaha keripik singkong yang memasarkan produknya hingga ke kota kabupaten. Namun produknya masih terbatas pada rasa standar, yaitu asin dan manis. Dengan pengembangan rasa dan teknologi menggunakan alat yang lebih modern ini mereka optimis dengan prospek usaha tersebut.

b. Perlu ada pendampingan sampai kepada aspek legal dengan mengurus izin PIRT, sehingga produk olahan yang dihasilkannya memenuhi standar kesehatan dan menjadi produk olahan yang legal untuk menjangkau pasar yang lebih luas.

c. Perawatan alat secara rutin dan mandiri, antara lain dengan selalu mengasah pisau alat perajang singkon agar tetap berfungsi dengan baik .

\section{KESIMPULAN}

Kegiatan pendampingan dan pemberdayaan warga transmigran di Kimtrans Sungai Besar SP-1 selama empat bulan berhasil membangun kesadaran, ketrampilan dan praktek kewirausahaan untuk mengolah potensi hasil pertanian warga transmigran menjadi bahan pangan yang mempunyai nilai tambah (added value ) ekonomi melalui pemanfaatan bantuan peralatan pengolahan pangan.

\section{UCAPAN TERIMA KASIH}

Ucapan terima kasih ditujukan kepada Kementerian Desa, Pembangunan Wilayah Tertinggal dan Transmigrasi serta PT. Shiddiq Sarana Mulya, Jakarta yang telah memfasilitasi pelaksanaan kegiatan pengabdian kepada masyarakat ini.

\section{REFERENSI}

[1] Setiawan, Bayu. 2011. Program Transmigrasi: Upaya Mengatasi Permasalahan Kependudukan dan Meningkatkan Kesejahteraan Masyarakat, Pertumbuhan Penduduk dan Kesejahteraan, Jakarta: LIPI Press.

[2] Prihatin, R.B. 2012. Revitalisasi Program Transmigrasi. E-jurnal di alamat

http://jurnal.dpr.go.id/index.php/aspiras i/article/view/487/383

[3] Mubyarto, 2000. Membangun Sistem Ekonomi, Cet 1, Penerbit BPFE, Yogyakarta.

[4] Sumodiningrat, G. 2000. Visi dan Misi Pembangunan Pertanian Berbasis Pemberdayaan. Penerbit IDEA, Yogyakarta.

[5] Cholitin, E.E dan Juni Thamrin.1997. Pemberdayaan Dan Refleksi Finansial Usaha Kecil Di Indonesia. Penerbit Yayasan Akita, Bandung. 